\title{
Estimation of the Eyeball and Orbital Volume Using the Cavalieri Principle on Computed Tomography Images
}

\author{
Niyazi Acer ${ }^{1}$, Mehmet Demir², Tolga Uçar ${ }^{3}$, Hıdır Pekmez ${ }^{4}$, Atilla Göktaş ${ }^{5}$ \\ ${ }^{1}$ Department of Anatomy, Faculty of Medicine, Erciyes University, Kayseri, Turkey \\ ${ }^{2}$ Health Services Vocational School, December 7 University, Kilis, Turkey \\ ${ }^{3}$ Department of Eye Diseases, Muğla State Hospital, Muğla, Turkey \\ ${ }^{4}$ School of Health Sciences, Nursing Department, , Fırat University Elazığ, Turkey \\ ${ }^{5}$ Department of Statistics, Faculty of Arts and Sciences, Muğla University, Muğla, Turkey
}

\section{ABSTRACT}

Objective: The volumes of the eyeball and orbit have been the subject of a few studies, yet none of them have used stereological methods to estimate the volume. In the present study, we estimated the volumes of the eyeball and orbita in normal healthy men and women using the stereological method.

Material and Methods: We estimated the volume of the eyeball (VE) and the volume of the orbit (VO) in normal men and women using the Cavalieri principle as a combination of a point-counting technique. We used computed tomography scans taken from 31 subjects (12 men and 19 women).

Results: The mean ( \pm SD) VO in the female subjects was $18.47 \pm 2.52 \mathrm{~cm}^{3}$ on the right side and $18.16 \pm 2.52 \mathrm{~cm}^{3}$ on the left side. The VE was $7.45 \pm 1.19$ $\mathrm{cm}^{3}$ and $7.45 \pm 1.25 \mathrm{~cm}^{3}$ on the right and left sides, respectively. The mean $( \pm \mathrm{SD})$ VO in the male subjects was $22.35 \pm 3.05 \mathrm{~cm}^{3}$ on the right side and $22.71 \pm 2.80 \mathrm{~cm}^{3}$ on the left side. The VE was $7.32 \pm 0.74 \mathrm{~cm}^{3}$ and $7.61 \pm 1.04 \mathrm{~cm}^{3}$ on the right and left sides, respectively.

Conclusion: Measurement by the technique described is an easy, and quick method of assessing the volumes of the eyeball and orbit.

Key Words: Tomography computed, orbit, eye, anatomy, stereology, cavalieri principle

Received: 20.10 .2009

Accepted: 22.02 .2010

\section{Introduction}

Stereology is a sampling technique used to generate mathematically unbiased estimates of geometric properties of three-dimensional structures based on two-dimensional slices of the object ${ }^{1}$. Using this method, volume and surface area estimates may be generated in a robust, reliable and time-efficient manner based on computed tomography (CT) scanning and magnetic resonance (MR) images $(1,2)$.

Point counting and planimetry are two techniques for estimating the volume based on the Cavalieri principle (3-6). Various software such as OSIRIS, DicomWorks and ImageJ etc. have recently been used for planimetric measurement (7-9).

There is only one study reporting that the application of image analysis system to MR images may provide an unbiased estimation of the both VE and VO (10). They did not use the stereological approach for volume estimation. Cahu et al. $(10,11)$ used the polygon regions of interest (ROI) function in OSIRIS for the estimation of orbital and eyeball volume. Orbital volumes were found by drawing ROI manually on each T1-weighted MR orbit scan using a stylus on a drawing tablet connected to the computer (11).
In the present study, we estimated the volume of eyeball and orbit in normal healthy men and women using the stereological method.

\section{Materials and Methods}

The study group was composed of 40 volunteer subjects (20 women, 20 men) 35-45 years old (mean \pm SD, $40 \pm 6$ years). The mean ages were $41.5 \pm 3.1$ and $39.4 \pm 5.3$ years old for the men and women, respectively. These subjects had presented to the ophthalmology clinic between January 2007 and February 2007. All subjects were emmetropic and excluded if they had any history of serious head trauma, metabolic or systemic diseases, and glaucoma or other ophthalmologic diseases. Nine subjects were excluded from our study according to our criteria. In this study 31 (19 women and 12 men) subjects were used. The remaining subject age ranged between 36-45 years old (mean \pm SD, $41 \pm 6$ years).

Official permission to conduct the study was obtained from the University of Muğla in Turkey and Muğla state hospital administrators. All participants provided informed, written consent. 
Prior to the CT scanning, all subjects were examined by an ophthalmologist and later scanned in a supine position using a conventional non-spiral scanner without contrast media. For this purpose, CT imaging was performed using a CT scanner (Somotom ARC, Siemens, Germany). Contiguous axial images were acquired with the use of $2 \mathrm{~mm}$ slice thickness, 200x200 $\mathrm{mm}$ field of view and 130 kilo voltage peak $(\mathrm{kVp})$ and 70 tube current-time product ( $m A s)$. Each CT scan was displayed in a $320 \times 320$ image matrix. The basic data set comprised between 17 and 21 sections. VE and VO were estimated using the Cavalieri principle as a point-counting.

The margins of the bony orbit were defined by the orbital walls and the orbital entrance. These were formed by the superior, lateral, medial and inferior orbital rim. The posterior boundary of the orbit was defined by a line connecting the medial and lateral walls of the optic foramen within the orbit. The anterior boundary was defined by the corresponding most anterior bone edges of the medial and lateral orbital walls. The optic canal, the nasolacrimal duct, and the pterygopalatine fossa were not included (12-16). The margins of the eyeball were defined by the outer border of the sclera and included the anterior chamber (11) (Fig 1).

\section{Point-counting method}

The point-counting method consists of overlying each selected section with a regular grid of test points, which is randomly positioned. After each superimposition, the number of test points hitting the structure of interest on the sections is counted, and the volume of the structure is estimated by multiplying section thickness, total number of points and the representing area per point in the grid $(3,4)$.

CT images were printed on film in square frames measuring 6 by $6 \mathrm{~cm}$. The films were placed on a negatoscope and the transparent square grid test system with $d=0.20,0.25 \mathrm{~cm}$ between test points was superimposed, randomly covering the entire image frame (Fig. 1). A square grid test system with $d=$ 0.20 and $0.25 \mathrm{~cm}$ between test points i.e., 0.04 and $0.0625 \mathrm{~cm}^{2}$ representing area per point, were used to estimate the sectioned surface area of the slices. The points hitting the eyeball and orbit sectioned surface area were counted for each section and the VE and VO were estimated using the modified formula for volume estimations of radiological images $(2,3,6,7-9)$.

$$
V=t \times\left[\frac{S U \times d}{S L}\right]^{2} \times \sum P
$$

Calculations were carried out as follows: $t$ represents the section thickness of consecutive sections, SU the scale unit of the printed film, $d$ the distance between the test points of the grid, SL the measured length of the scale printed on the film and $\Sigma P^{\prime}$ is the total number of points hitting the sectioned cut surface areas of the eyeball.

\section{Coefficient of error (CE)}

In the Cavalieri principle, the researcher obtains data called coefficient of error (CE) to evaluate the reliability of the point density of the grids and sectioning intervals. The CE or relative standard error represents the precision of the volume estimate obtained using the Cavalieri principle. Since consecutive section cut surface areas are not independent quantities, conventional statistical formulae of CE cannot be applied to determine the variance of their sum $(17,18)$.

The precision of the above VE and VO volume estimations was expressed as CE and was calculated as follows:

$$
C E=\left(\sum_{i=1}^{m} P_{i}\right)^{-1}\left[\frac{1}{12}\left(3 \sum_{i=1}^{m-2} P_{i}^{2}+\sum_{i=1}^{m-2} P_{i} P_{i+1}-4 \sum_{i=1}^{m-1} P_{i} P_{i+1}\right)+0.0543\left(\frac{B}{\sqrt{A}}\right)\left(m \sum_{i=1}^{m} P_{i}\right)^{1 / 2}\right]^{1 / 2}
$$

where $B$ and $A$ denote the mean boundary length and the mean area of the eyeball and orbit, respectively, $\mathrm{Pi}$ is the number of points counted on a section $\mathrm{i}$, and $\mathrm{m}$ is the total number of sections through the eyeball and orbit. The dimensionless quotient $B / \sqrt{ } A$ is known as shape coefficient; it may be considered stable for each particular object (17).

Quantity A was measured by point counting using a grid of test points, while quantity $B$ was measured by counting the number of intersections with a square grid of test lines. To calculate the quotient $B / \sqrt{ } A$ for a patient, all $C T$ sections depicting eyeball and orbit were used. Values of $B / \sqrt{ } A$ were obtained for the all control and patients of the study. The above mean value was used for the error prediction of all VE and VO estimations $(17,18)$.

There are many approaches for the estimation of CE of individuals. For the volume estimations, Gundersen and Jensen (17) proposed a new approach evaluating the effect of both the sectioning and the point superimposition on the sections for the Cavalieri principle. They also improved the CE estimation process and slightly changed the formulae (18). In the presented study we used their final CE prediction formula.

Measurements were repeated three times and the average taken. All calculations and other related data were obtained as a spreadsheet using Microsoft Excel. After the initial setup and preparation of the formulas, the point counts, formulas and other data were entered for each subject and the final data were obtained automatically. The stereological technique may be optimized by systematically sampling CT sections and by determining an optimum distance between test points of the grid $(8,19)$.

\section{Statistics}

The data collected were processed by the SPSS/ version 10.0.1 statistical software (SPSS Inc,. IL.USA). Values are expressed in terms of the mean and standard deviation (SD). The difference in orbit and eyeball volumes between genders was analyzed using the independent $t$ test. The differences of the estimated volumes obtained by right and left sides were compared using paired t test. Correlations between different parameters were tested by Pearson correlation test. The statistic power was analyzed by power analysis using Minitab program.

In our study, to have a power of $80 \%$ would necessitate a sample size of 40 subjects. The power of the performed test $(0.05)$ is above the desired power of 0.80 for EV and VO. All reported significance levels are two-tailed and $p<0.05$ is considered statistically significant. 


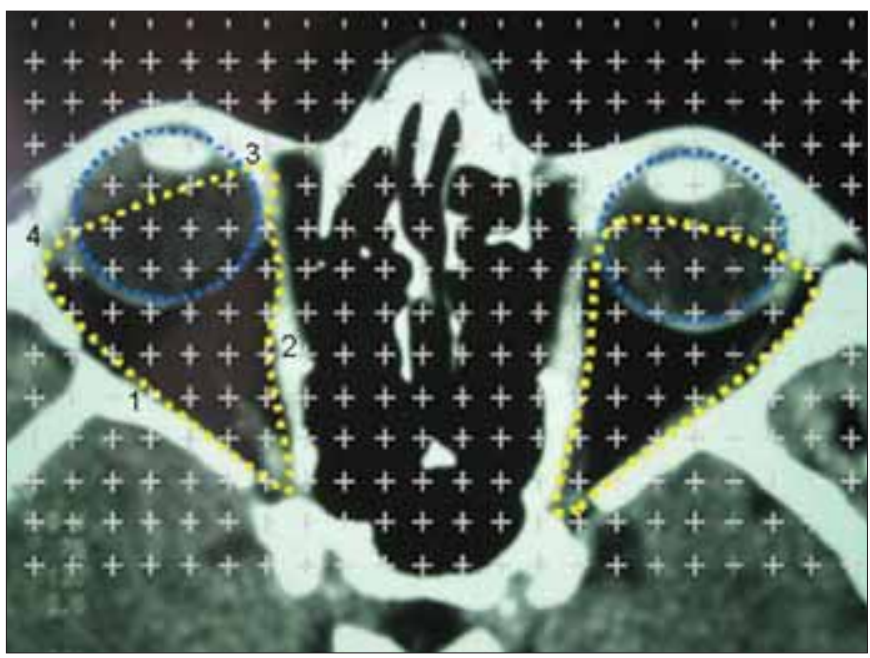

Figure 1. An axial CT scan with a point counting grid superimposed on orbital cavity and eyeball.1: Lateral orbital wall; 2: Medial orbital wall; 3: The anterior bone edges of the medial orbital wall; 4: The anterior bone edges of the lateral orbital wall

\section{Results}

The VO ranged from 14.20 to $27.38 \mathrm{~cm}^{3}$. The VE ranged from 5.71 to $10.19 \mathrm{~cm}^{3}$. Table 1 presents the data for all subjects.

The mean $( \pm S D) \mathrm{VO}$ in women was $18.47 \pm(2.52) \mathrm{cm}^{3}$ on the right side and $18.16 \pm(2.52) \mathrm{cm}^{3}$ on the left side. The VE was $7.45 \pm(1.19) \mathrm{cm}^{3}$ and $7.45 \pm(1.25) \mathrm{cm}^{3}$ on the right and left sides, respectively. The mean $( \pm S D) \mathrm{VO}$ in males was $22.35 \pm(3.05) \mathrm{cm}^{3}$ on the right side and $22.71 \pm(2.80) \mathrm{cm}^{3}$ on the left side. The VE was $7.32 \pm(0.74) \mathrm{cm}^{3}$ and $7.61 \pm(1.04)$ $\mathrm{cm}^{3}$ on the right and left sides, respectively. There were no statistically significant differences between genders and right and left sides for VE ( $p>0.001)$ but there was a statistically significant difference between genders and right and left sides for $V O(p<0.001)$. The VO rating for men was higher than for women (Table 2).

The differences between right and left side estimates were not significant between genders for both VO and VE ( $p>0.001)$. There was a strong correlation between right and left VO and VE values ( $r=0.958,0.951$, respectively). The details of the statistical analysis are shown in Table 3.

The VO was poorly correlated with the VE $(r=0.279)$ on the right side but there was a slight correlation on the left side $(r=0.337)$.

The mean coefficient of error (CE) obtained by applying $0.20 \mathrm{~cm}$ and $0.25 \mathrm{~cm}$ test points were estimated at $<2 \%$, that using a $0.25 \mathrm{~cm}$ test point at $3 \%$ for orbit volume. The means of the point counting time per orbit were 5:20 min and 3:47 $\min$ for $\mathrm{d}=0.20$ and $0.25 \mathrm{~mm}$, respectively.

The point-counting time per eyeball was 3:05 min and 1:92 min for $d=0.20$ and $0.25 \mathrm{~mm}$. respectively. The mean CEs for the VE estimates derived from the technique of $d=0.20$ and $0.25 \mathrm{~mm}$ were 2 and $2 \%$, respectively.

The mean of estimated orbit and eyeball volumes obtained from the 0.20 and $0.25 \mathrm{~mm}$ test point series did not significantly differ statistically using the point-counting method ( $p=0.798$ and 0.813 , respectively).
Table 1. Data for all subjects and estimates of eyeball and orbital volumes

\begin{tabular}{|c|c|c|c|c|}
\hline \multirow[b]{2}{*}{$\begin{array}{l}\text { Case } \\
\text { no/Gender }\end{array}$} & \multicolumn{2}{|c|}{ Right } & \multicolumn{2}{|c|}{ Left } \\
\hline & $\begin{array}{c}\text { Orbital } \\
\text { volume } \\
\left(\mathrm{cm}^{3}\right)\end{array}$ & $\begin{array}{c}\text { Eyeball } \\
\text { volume } \\
\left(\mathrm{cm}^{3}\right)\end{array}$ & $\begin{array}{c}\text { Orbital } \\
\text { volume } \\
\left(\mathrm{cm}^{3}\right)\end{array}$ & $\begin{array}{c}\text { Eyeball } \\
\text { volume } \\
\left(\mathrm{cm}^{3}\right)\end{array}$ \\
\hline $1 / \mathrm{W}$ & 0.26 & 10.21 & 20.14 & 10.16 \\
\hline $2 / \mathrm{W}$ & 20.43 & 8.93 & 18.82 & 8.32 \\
\hline $3 / \mathrm{W}$ & 17.29 & 6.25 & 16.19 & 6.10 \\
\hline $4 / \mathrm{W}$ & 15.49 & 6.80 & 14.62 & 6.96 \\
\hline $5 / \mathrm{W}$ & 18.47 & 6.73 & 18.21 & 6.70 \\
\hline $6 / \mathrm{W}$ & 13.77 & 5.97 & 14.63 & 5.45 \\
\hline $7 / \mathrm{W}$ & 14.99 & 7.93 & 14.37 & 8.40 \\
\hline $8 / W$ & 20.18 & 6.49 & 19.99 & 6.80 \\
\hline $9 / \mathrm{W}$ & 18.32 & 6.49 & 18.94 & 6.51 \\
\hline $10 / \mathrm{W}$ & 21.32 & 7.10 & 20.12 & 7.19 \\
\hline $11 / \mathrm{W}$ & 16.73 & 6.87 & 17.78 & 6.71 \\
\hline $12 / \mathrm{W}$ & 23.78 & 7.65 & 23.93 & 8.14 \\
\hline $13 / \mathrm{W}$ & 20.88 & 7.62 & 21.74 & 7.57 \\
\hline $14 / \mathrm{W}$ & 17.11 & 6.71 & 16.53 & 6.82 \\
\hline $15 / \mathrm{W}$ & 17.81 & 7.86 & 17.35 & 7.97 \\
\hline $16 / \mathrm{W}$ & 17.11 & 6.30 & 17.80 & 6.21 \\
\hline $17 / W$ & 19.64 & 8.94 & 19.05 & 9.00 \\
\hline $18 / \mathrm{W}$ & 20.94 & 9.58 & 19.48 & 9.80 \\
\hline $19 / \mathrm{W}$ & 16.55 & 7.14 & 15.42 & 6.83 \\
\hline $1 / \mathrm{M}$ & 17.14 & 7.33 & 18.26 & 7.40 \\
\hline $2 / \mathrm{M}$ & 24.23 & 7.60 & 24.36 & 7.57 \\
\hline $3 / \mathrm{M}$ & 22.48 & 6.93 & 22.90 & 6.99 \\
\hline $4 / \mathrm{M}$ & 23.41 & 7.37 & 25.66 & 7.53 \\
\hline $5 / \mathrm{M}$ & 20.19 & 6.83 & 19.71 & 6.92 \\
\hline $6 / M$ & 17.68 & 8.07 & 20.95 & 9.24 \\
\hline 7/M & 20.25 & 6.22 & 19.25 & 6.36 \\
\hline $8 / \mathrm{M}$ & 25.20 & 8.94 & 24.67 & 9.68 \\
\hline 9/M & 24.24 & 7.67 & 24.41 & 8.11 \\
\hline $10 / \mathrm{M}$ & 21.98 & 6.87 & 21.47 & 6.91 \\
\hline $11 / \mathrm{M}$ & 27.33 & 7.66 & 27.42 & 8.25 \\
\hline $12 / \mathrm{M}$ & 24.10 & 6.41 & 23.46 & 6.39 \\
\hline Min-Max & $13.77-27.33$ & $5.97-10.21$ & $14.37-27.42$ & $5.45-10.16$ \\
\hline
\end{tabular}

\section{Discussion}

It is known that VO increases in buphthalmos and decreases in anophthalmia compared with the opposite orbit for the normal eye (20).

VE plays an important role in some ocular diseases such as microphthalmus, buphthalmus, macrophthalmus etc. (21) Microphthalmus may also be associated with developmental anomalies of specific segments of the eye. Macrophthalmus is said to be present when all dimensions of the eye are increased but glaucoma is not present (21). 
Table 2. Mean \pm SD forboth sexes and statistical significance (independent $t$ test)

\begin{tabular}{|c|c|c|c|c|c|c|}
\hline \multirow[b]{2}{*}{ Genders/sides } & \multicolumn{3}{|c|}{$\begin{array}{l}\text { Orbital volume } \\
\quad(\text { Mean } \pm \text { SD) }\end{array}$} & \multicolumn{3}{|c|}{$\begin{array}{l}\text { Eyeball volume } \\
\quad(\text { Mean } \pm \text { SD) }\end{array}$} \\
\hline & Men & Women & $P^{*}$ & Men & Women & $P^{*}$ \\
\hline Right & $22.35 \pm 3.05$ & $18.47 \pm 2.52$ & 0.001 & $7.32 \pm 0.74$ & $7.45 \pm 1.19$ & 0.001 \\
\hline Left & $22.71 \pm 2.80$ & $18.16 \pm 2.52$ & 0.747 & $7.61 \pm 1.04$ & $7.45 \pm 1.25$ & 0.730 \\
\hline
\end{tabular}

Table 3. Statistical Comparisons and Agreements between the left and right sides

\begin{tabular}{|lccccc|}
\hline & Mean \pm SD $\left(\mathrm{cm}^{3}\right)$ & $\begin{array}{c}\text { Paired Differences } \\
\text { between the left } \\
\text { and right side (Mean) }\end{array}$ & Std. Deviation & Sig. & $\begin{array}{c}\text { Pearson } \\
\text { Correlation (r) }\end{array}$ \\
\hline Orbital volume (right) & $19.97 \pm 3.30$ & -0.11 & 0.345 & 0.779 & 0.958 \\
Orbital volume (left) & $19.92 \pm 3.43$ & & & & 0.951 \\
Eyeball volume (right) & $7.40 \pm 1.03$ & 0.05 & 1.058 & 0.078 & 0.951 \\
Eyeball volume (left) & $7.51 \pm 1.16$ & & & & \\
\hline
\end{tabular}

In previous studies measuring MRI and CT scanning, VE and VO were estimated using planimetry, but the coefficient of error was not calculated. Furthermore, none of these studies used stereological methods to estimate the volume (10-13, 22-24).

The mean VE found in this study was greater than that found by Chau et al. (10) (mean volume $6.70 \mathrm{~cm}^{3}$ ) and less than those results found by Bite et al. (22) (mean volume $8.94 \mathrm{~cm}^{3}$ ), Thaller (24) (mean volume $8.15 \mathrm{~cm}^{3}$ ) and Hahn et al. (23) (mean volume $\left.9.26 \mathrm{~cm}^{3}\right)$. It is also noteworthy that the methods used by Bite et al. (22) and Thaller (24) to determine eyeball volume were different. Bite et al. used CT images while Thaller used a water displacement method to find the VE.

Acer et al. (25) stated that the mean $\pm(S D)$ VE values obtained by the planimetric method were $7.49 \pm 0.79$ and $7.06 \pm 0.85 \mathrm{~cm}^{3}$ in men and women, respectively. By using point-counting method, the mean $\pm(S D)$ values were recorded as $7.48 \pm 0.85$ and $7.21 \pm 0.84 \mathrm{~cm}^{3}$ in men and women, respectively. Our mean VE was similar to those reported in the Acer et al. studies.

Chau et al. (11) estimated the age of maturity of orbit growth at 16.1 years old. At this age, the mature orbit volume was $21 \mathrm{~cm}^{3}$. There were 81 subjects, aged from 1 to 42 years included in their study. The orbit volume ranged from 11.56 to $25.50 \mathrm{~cm}^{3}$. More recently, Chau et al. (11) reported that volumes ranged from 15.96 to $24.89 \mathrm{~cm}^{3}$ (mean volume $=20.94$ $\mathrm{cm}^{3}$ ). We compared the VO data from our subjects who were aged from 18 to 40 years old with those presented in the study of Furuta (26) and Chau (11). Male and female subjects in Furuta's study had a slightly higher VO than those in our study, but Chau's result was similar to our subjects' result.

Acer et al. (27) stated that the means $\pm(S D)$ of the VO measured by the water filling method and the point counting method were $17.84 \pm 1.56 \mathrm{~cm}^{3}, 17.05 \pm 1.69 \mathrm{~cm}^{3}$, respectively. Our mean VO was slightly higher than that reported in Acer's study, but lower than those reported in other studies $(12,16)$. Acer et al. (27) used dry skull for orbital volume estimation. Chau's study was carried out on MR images. The VO measurement in Furuta's study was carried out on CT images and no calibration was mentioned in the study. The difference in VE and VO found may be attributable to the differences in methodology used in these studies.

Chau (7) stated that volumes of the eyeballs showed no significant gender effects ( $p>0.05)$. However, VO was significantly greater in men than women. We found that there was a statistically significant difference between men and women for VO $(p=0.000)$.

Sectional imaging modalities have provided an opportunity for volumetric quantification of the orbit and eyeball volume. MR imaging offers optimal soft tissue contrast resolution and multiplanar capability without the use of ionizing radiation. However, CT imaging is still a powerful modality for the detailed depiction of bony structures (8). CT has higher spatial resolution than $M R$, and therefore is better for imaging small structures, and for showing fine detail such as bony structures. The main virtue of spiral CT is the speed with which an area can be scanned, not the large anatomic area to be covered during each slice.

CT can produce the distinct contours of bones and the detailed depiction of bony structures, but it cannot show clear images of soft tissue $(3,8)$. Conversely, MRI shows the shape of soft tissue, but does not reveal the distinct contour of bones. However, the margins of the eyeball and bony orbit were defined easily on CT scans.

Orbital volume measurement after maxillofacial trauma provides valuable data for either estimating the severity of the injury or prevention of possible complications caused by enophthalmos (26). Congenital glaucoma is the result of developmental obstruction of intraocular fluid drainage, so that the pressure in the eye is raised and the globe becomes enlarged (21). Therefore, it can be useful to know the volume of the orbit and eyeball in order to monitor the effects of some diseases and plan treatment or surgical applications.

Although some methods of measuring VO from CT slices have been reported, many of these involve summation of areas obtained from several axial or coronal slices. Orbital vol- 
ume measurement with these methods is very time consuming and is generally not practical $(28,29)$. Their studies are mainly conducted to estimate the efficiency of the applied method.

There are many studies using planimetry and point-counting measurement for volume estimation in different organs $(3,6-9)$. Results of these studies showed good correlation and there was no statistical difference between techniques.

In conclusion, the current study describes the application of a stereological technique on CT scans for determining the eyeball and orbital volume. The method presented in our study is inexpensive and rapid, because the point counting method requires only 2 to 5 minutes per orbit and eyeball.

\section{Conflict of Interest}

No conflict of interest was declared by the authors.

\section{References}

1. Ronan L, Doherty CP, Delanty N, Thornton J, Fitzsimons M. Quantitative MRI: a reliable protocol for measurement of cerebral gyrification using stereology. Magn Reson Imaging 2006;24:265-72. [CrossRef]

2. Akbas H, Sahin B, Eroglu L, Odaci E, Bilgic S, Kaplan S, et al. Estimation of the breast prosthesis volume by the Cavalieri principle using magnetic resonance images. Aesth Plast Surg 2004;28:275-80. [CrossRef]

3. Acer N, Sahin B, Usanmaz M, Tatolu H, Irmak Z. Comparison of point counting and planimetry methods for the assessment of cerebellar volume in human using magnetic resonance imaging: A stereological study. Surg Radiol Anat 2008;30:335-9. [CrossRef]

4. Gong QY, Tan LT, Romaniuk CS, Jones B, Brunt JN, Roberts N. Determination of tumour regression rates during radiotherapy for cervical carcinoma by serial MRI: comparison of two measurement techniques and examination of intraobserver and interobserver variability. Br J Radiol 1999;72:62-72.

5. McEvoy F.J. An application of image processing techniques in computed tomography image analysis. Vet Radiol Ultrasound 2007;48:528-34. [CrossRef]

6. Sahin B, Ergur H. Assessment of the optimum section thickness for the estimation of liver volume using magnetic resonance images: a stereological gold standard study. Eur J Radiol 2006;57:96-101. [CrossRef]

7. Chau A, Fung K, Yip L, Yap M. Orbital development in Hong Kong Chinese subjects. Ophthalmic Physiol Opt 2004;24:436-9. [CrossRef]

8. Acer N, Sahin B, Bas O, Ertekin T, Usanmaz M. Comparison of three methods for the estimation of total intracranial volume: stereologic, planimetric, and anthropometric approaches. Ann Plast Surg 2007;58:48-53. [CrossRef]

9. Mazonakis M, Karampekios S, Damilakis J, Voloudaki A, Gourtsoyiannis N. Stereological estimation of total intracranial volume on CT images. Eur Radiol 2004;14:1285-90. [CrossRef]

10. Sahin B, Acer N, Sonmez OF, Emirzeoglu M, Basaloglu H, Uzun A, et al. Comparison of four methods for the estimation of intracranial volume: a gold standard study. Clin Anat 2007;20:766-73. [CrossRef]
11. Chau A, Fung K, Pak K, Yap M. Is eye size related to orbit size in human subjects? Ophthalmic Physiol Opt 2004;24:35-40. [CrossRef]

12. Deveci M, Ozturk S, Sengezer M, Pabuşcu Y. Measurement of orbital volume by a 3-dimensional software program: an experimental study. J Oral Maxillofac Surg 2000;58:645-8. [CrossRef]

13. Eppley BL, Holley S, Sadove AM. Experimental effects of intraorbital tissue expansion on orbitomaxillary growth in anophthalmos. Ann Plast Surg 1993;31:19-26. [CrossRef]

14. Bentley RP, Sgouros S, Natarajan K, Dover MS, Hockley AD. Normal changes in orbital volume during childhood. J Neurosurg 2002;96:742-6. [CrossRef]

15. Hintschich C, Zonneveld F, Baldeschi L, Bunce C, Koornneef L. Bony orbital development after early enucleation in humans. $\mathrm{Br} \mathrm{J}$ Ophthalmol 2001;85:205-8. [CrossRef]

16. McGurk M, Whitehouse RW, Taylor PM, Swinson B. Orbital volume measured by a low-dose CT scanning technique. Dentomaxillofac Radiol 1992;21:70-2.

17. Gundersen HJG, Jensen EB. The efficiency of systematic sampling in stereology and its prediction. J Microsc 1987;147:229-63.

18. Gundersen HJ, Jensen EB, Kiêu K, Nielsen J. The efficiency of systematic sampling in stereology-reconsidered. J Microsc 1999;193:199-211. [CrossRef]

19. Sahin B, Emirzeoglu M, Uzun A, Incesu L, Bek Y, Bilgic S, et al. Unbiased estimation of the liver volume by the Cavalieri principle using magnetic resonance images. Eur J Radiol 2003;47:164-70. [CrossRef]

20. Heinz GW, Clunie DA, Mullaney PB. The effect of buphthalmos on orbital growth in early childhood: increased orbital soft tissue volume strongly correlates with increased orbital volume. J AAPOS 1998;2:39-42. [CrossRef]

21. Osborne DR, Foulks GN. Computed Tomographic Analysis of Deformity and Dimensional Changes in the Eyeball. Radiology 1984;153:669-74.

22. Bite U, Jackson IT, Forbes GS, Gehring DG. Orbital volume measurements in enophthalmos using three-dimensional CT imaging. Plast Reconstr Surg 1985;75:502-8. [CrossRef]

23. Hahn FJ, Chu WK. Ocular volume measured by CT scans. Neuroradiology 1984;26:419-20. [CrossRef]

24. Thaller VT. Enucleation volume measurement. Ophthal Plast Reconstr Surg 1997;13:18-20. [CrossRef]

25. Acer N, Sahin B, Ucar T, Usanmaz M. Unbiased estimation of the eyeball volume using the Cavalieri principle on computed tomography images. J Craniofac Surg 2009;20:233-7. [CrossRef]

26. Furuta M. Measurement of orbital volume by computed tomography: especially on the growth of the orbit. Jpn J Ophthalmol 2001;45:600-6. [CrossRef]

27. Acer N, Sahin B, Ergür H, Basaloglu H, Ceri NG. Stereological Estimation of the Orbital Volume: A Criterion Standard Study. J Craniofac Surg 2009;20:921-5. [CrossRef]

28. Cooper WC. A method for volume determination of the orbit and its contents by high resolution axial tomography and quantitative digital image analysis. Trans Am Ophthalmol Soc 1985;83:546-609.

29. Koppel DA, Foy RH, McCaul JA, Logan J, Hadley DM, Ayoub A. The reliability of BAnalyze[ software in measuring orbital volume utilizing CT-derived data. J Craniomaxillofac Surg 2003;31:88-91. [CrossRef] 